\title{
Analysis of The Results of Cervical Cancer Screening Campaigns at Owendo's CHU Maternity Hospital
}

\author{
Sima Ole B ${ }^{1 *}$, Mounguengui CO${ }^{1}$, Mba Edou SG ${ }^{1}$, Madi TG ${ }^{1}$, Mewie Lendzinga ${ }^{1}$, Bang Ntamack JA ${ }^{2}$, Mayi \\ Tsonga $S^{2}$, Ngou Mve Ngou JP2 and Meye JF ${ }^{2}$ \\ ${ }^{1}$ Owendo Obstetric Gynecology Service, Owendo, Africa \\ ${ }^{2}$ Department of Obstetric Gynecology Libreville Medical School, Owendo, Africa
}

*Corresponding author: Boniface Sima Ole, Department of Obstetric Gynecology, Owendo, Gabon.

Received Date: July 08, 2019

Published Date: July 19, 2019

\begin{abstract}
Introduction: Cervical cancer is a common cancer. It is accessible for early detection and treatment. The aim was to describe and analyze the lesions observed and their management with a view to reducing the rate of female cancer morbidity and death in Gabon.

Methodology: This was a 31-day descriptive and analytical cross-sectional study over two successive years (2017 and 2018), 62 days. All women who consulted for cervical cancer screening were enrolled. Visual inspection methods (VIA/IVIL) were the procedure method, a biopsy was indicated or not, and management was codified. A simple descriptive analysis and the results expressed as a percentage and on average were performed.

Results: The target population was 629 women (45.45\%) in 2017 and 755 (54.55\%) in 2018, or 1,384 women and an increase of 9.10\%. The average age of women was $37.02 \pm 1.2$ years [15-72 years]. The $25-39$ age groups were the most represented $(51.5 \%), 24.4 \%$ were over 50 and $68.56 \%$ were single. There were as many IELG $(4.77 \%)$ as there were IELHG (4.48\%). Eight cases of invasive cancer (0.58\%) were found including 3 cases in the 15-24 age. All precancerous lesions were immediately treated, and all 8 cancers were surgically treated after Multidisciplinary Consultation Meeting (MCM)
\end{abstract}

Conclusion: Organized screening and efficient use of resources reduce the mortality of women from cervical cancer.

Keywords: Cervical cancer-screening; VIA/VIL; Mother mortality

\section{Introduction}

The cervix corresponds to the lower $1 / 3$ of the uterus. Its projects in the vagina and is accessible through speculum examination. Cervical cancer is a slow-onset cancer that occurs after several years. It is thus accessible for early detection and treatment. According to WHO, in 2012, 528,000 new cases of cervical cancer were diagnosed worldwide. A large majority of these cases $(85 \%)$ were in less developed regions. In the same year, 266000 women died as a result of cervical cancer worldwide; nearly 9/10 deaths, i.e. a total of 231000 deaths among women living in low- and middle-income countries [1]. These disparities are related to the relative lack of effective early prevention, detection and treatment programs for precancerous lesions. In Gabon after Globocan 2012, cervical cancer is the first female cancer in the gynecological and mammary sphere with an incidence of $118 / 100000$, followed by breast cancer $98 / 100000$ [2]. At the moment, unpublished hospital figures rank $2^{\text {nd }}$ behind breast cancer ( $36 \%$ vs $52 \%$ ). It is often diagnosed in the advanced stage with mortality consequences $(14,7 / 10000)[3,4]$. Nowadays, the role of human papillomavirus (HPV) infection is clearly established in the onset of cervical cancer. It is a common infection; high-risk oncogenic strains (HR-HPV) are the main risk factors for cervical cancer. The duration of the infection and its persistence were associated with the development of transient, persistent, or cancer-developing intra-epithelial precancerous lesions. Other risk factors are associated with the occurrence of cervical cancer, in particular immunosuppression, parity and adverse socio-economic conditions [5]. Currently available preventive vaccines target strains 6, 11, 16 and 18 . Cervical cancer is thus an accessible cancer for prevention and early treatment [6]. A woman who is screened between 30 and 40 years of age would have a reduced risk of developing cervical cancer from 
25 to $36 \%$ [7]. Screening is based on visual inspection methods after the application of acetic acid (VIA) to Lugol VIL), cytology and histological analysis. Visual inspection is a simple, reproducible, less expensive screening approach adapted to the economic realities of developing countries [8,9]. In our practices, cervical cancer screening is not systematic, and it is not widely known to populations. We take stock of 2 years of cervical cancer screening during mass screening campaigns. The aim was to describe and analyze the lesions observed and how they were handled.

\section{Patients and Methods}

This is a descriptive and analytical cross-sectional study of 31 days in October during two successive years (2017 and 2018) at the maternity hospital of CHU Owendo, 62 days. Since 2015, in October called rose, thanks to Sylvia Bongo Ondimba Foundation a mass screening campaign for gynecological and breast cancers has been organized. Screening for cervical cancer is the most accessible, cheaper and easy to achieve. Following a several-week audio-visual campaign, the target population was women of all ages who wanted to be screened and seen in consultation during the study period. There are three pools. A reception pool consisting of paramedics for the reception of women and the creation of an information sheet including identification, gynecological and obstetric history and anthropometric and vegetative parameters. The other 2 pools were intended for screening and this was done either by midwives and residents and, if necessary, by obstetrician gynecologists. After a complete gynecological examination, the screening consisted of a visual inspection with acetic acid (VIA) and a visual inspection with Lugol (VIL) in direct vision or by colposcopy when the result was considered positive. The visual inspection is carried out in an illuminated room, woman in gynecological position. After a speculum is laid, the cervix is examined without preparation, then applied acetic acid to 4\% (VIA) and then applied Lugol (VIL). The result is said to be positive when there is well defined bleaching close to the VIA pavimentocylindric junction area and/or coloring in saffron yellow or mustard yellow for VIL. Screening continues with a biopsy when the results of visual tests are difficult or positive interpretations. This biopsy is made with a special biopsy clip in areas of the cervix where the examination has been positive or where there are anomalies that lead to a suspicion of cancer. The sample was collected in a bottle containing formaldehyde and labeled with the woman's name and date of collection and then handed over to the woman for the medical laboratory of anatomy pathology. This biopsy was made by appointment and was paid for by the woman. Its cost was 15 DUS (10.000 FCFA). Once examined, the biopsies were classified into different stages: normal, intraepithelial cervical neoplasia (in English: cervical intraepithelial neoplasia (CIN) or invasive cancer. The lesions were classified as low-grade CIN I (IELG), or high-grade CIN II and CIN III (IELHG) lesions according to BETHESDA classification, forming all CIN2+ categories according to the thickness of the abnormal epithelium. The management consisted of monitoring, conducting conization with electric bistoury or diadermal cove or hysterectomy. For women with invasive cancer, an additional consultation was carried out to determine the evolutionary stage, to carry out an extension check and to propose a therapeutic scheme after Multidisciplinary Consultation Meeting (MCM). No destructive methods were used. A data collection sheet was developed, and the following parameters were studied: age, occupation, marital status, age of first sexual intercourse, number of sexual partners since the first sexual intercourse, concept of prior testing, management, parity, test results in Lugol, histology and treatment methods. Following the results of the visual tests, 2 groups were formed. The negative visual testing group (A) and positive testing groups (B). Exclusions were for women with vaginal losses (bleeding or leucorrhea), those with hysterectomy, incomplete records, and women who did not provide the results of histological analysis. The data was entered on Microsoft Excel 2010 version 14.5.1 and then imported and analyzed on Epi info 7. Results were expressed as a percentage for qualitative variables and an average \pm standard deviation for quantitative variables. These variables were compared with each other using the Khi2 test, the Khi2 corrected by Yates (n between 3 and 4$)$ and the exact Fisher test $(n<3)$. The difference was significant for $\mathrm{p}$-value $<0.05$.

\section{Results}

During the study period, 1,471 women were registered for screening. We retained 1384 or $94.09 \%$. In October 2017, 629 women (45.44\%) and 755 (54.55\%) in October 2018, an increase of $9.10 \%$. During this period, 10,764 visits were recorded, $12.86 \%$ of them for cervical cancer screening. The majority of these were from the municipality of Owendo $60.11 \%$ (832).

\section{Socio-epidemiological and gynecological characteristics}

The average age of women was $37.02 \pm 1.2$ years (15-72 years). Age groups 25-39 were the most represented $52.3 \%$ and $22.7 \%$ were over 50 . The proportion of children under 24 was $8.5 \%$. The majority of women were single (68.56\%), educated $(83.1 \%)$ and $64.1 \%$ had a source of income. In terms of the number of sexual partners, they reported having 1 to 22 sexual partners with an average of $8.02 \pm 1.3$ and $25.07 \%$ (347) reported having more than 10 sexual partners. The age of first sexual intercourse was between 10 and 29 years and an average of $15.7 \pm 2.3$ years. Most women were multigested $(72 \%)$, had an average parity of $3.1 \pm 2.3$ and $33.8 \%$ had more than 3 pares. At the time of the study, $22.69 \%$ (314) reported using contraception and the majority $(78.88 \%)$ reported using estrogen progestin pills (Table 1). The concept of sexually transmitted infection was found in $63.73 \%$ (882) of women and 1214 (87.72\%) had never performed prior screening.

Table 1: Socio-epidemiologic characteristics.

\begin{tabular}{|c|c|c|}
\hline \multicolumn{2}{|l|}{ Parameters Studied } & n \\
\hline Ages (an) & \multicolumn{2}{|l|}{} \\
\hline $15-24$ & 118 & 8,5 \\
\hline $25-39$ & 724 & 52,3 \\
\hline $40-50$ & 228 & 16,5 \\
\hline Plus de 50 & 314 & 22,7 \\
\hline
\end{tabular}




\begin{tabular}{|c|c|c|}
\hline \multicolumn{3}{|l|}{ Professional } \\
\hline Student & 263 & 19,00 \\
\hline Official & 383 & 27,67 \\
\hline Private & 504 & 36,42 \\
\hline No jobs & 234 & 16,91 \\
\hline \multicolumn{3}{|l|}{ Marital status } \\
\hline Single & 949 & 68,56 \\
\hline Couples & 435 & 31,44 \\
\hline \multicolumn{3}{|l|}{ Gestity } \\
\hline $0-2$ & 388 & 28,03 \\
\hline $3-5$ & 264 & 19,07 \\
\hline$>5$ & 732 & 52,90 \\
\hline \multicolumn{3}{|l|}{ STI* background } \\
\hline Yes & 882 & 63,73 \\
\hline No & 502 & 36,27 \\
\hline \multicolumn{3}{|l|}{ Sexual partners } \\
\hline 1 & 81 & 5,85 \\
\hline $2-5$ & 522 & 37,72 \\
\hline $6-10$ & 434 & 31,36 \\
\hline Plus de 10 & 347 & 25,07 \\
\hline
\end{tabular}

*Sexual transmissible Infection

\section{Test results}

Table 2: Col iodo-negative pass divided by age, management, number of partners and marital status.

\begin{tabular}{|c|c|c|c|}
\hline \multirow{2}{*}{ Parameters } & \multicolumn{2}{|c|}{ VIL } & \multirow{2}{*}{$\mathbf{p}$} \\
\hline & Negative (n) & Positive (n/\%) & \\
\hline \multicolumn{4}{|l|}{ Age } \\
\hline $15-24$ & 100 & $18 / 15,25$ & 0,566 \\
\hline $25-39$ & 573 & $151 / 20,86$ & \\
\hline $40-50$ & 182 & $46 / 20,18$ & \\
\hline Plus de 50 & 249 & $65 / 20,70$ & 0,000 \\
\hline \multicolumn{4}{|l|}{ Management } \\
\hline $0-2$ & 351 & $37 / 09,54$ & \\
\hline $3-5$ & 222 & $42 / 15,91$ & 0,000 \\
\hline$>5$ & 531 & $201 / 27,46$ & \\
\hline \multicolumn{4}{|l|}{ Partner count } \\
\hline 1 & 72 & $09 / 10,98$ & \\
\hline $2-5$ & 485 & $37 / 07,09$ & 0,000 \\
\hline $6-10$ & 387 & $47 / 10,83$ & \\
\hline Plus de 10 & 160 & $187 / 53,89$ & \\
\hline \multicolumn{4}{|l|}{ Marital status } \\
\hline Single & 728 & $221 / 23,29$ & 0,000 \\
\hline Couples & 376 & $59 / 13,56$ & \\
\hline
\end{tabular}

The examination of the cervix without preparation revealed 672 cervices (red 48.55\%) including 72 (10.71\%) suspicious lesions and 712 collars of normal appearance (rosé 51.45\%). Visual inspection of the cervix after application of acetic acid and then of the colposcopy coupled Lugol resulted in the following results: by VIA, 145 (10.47\%) university collar workers were identified, 72 (5.20\%) in 2017 and 73 (5.27\%) in 2018. By VIL, 280 (20.23\%) iodine-negative passes were detected, 126 (9.11\%) in 2017 and

$154(11.12 \%)$ in 2018, including $72(25.71 \%)$ collar-like collars (bounce) riddle). The cervix was even more iodo-negative because the woman was single $(\mathrm{p}=0.000)$. The same was true for age groups 25-39 (20.86\%), management and high partner numbers ( $p$ $=0.000)$ (Table 2).

\section{History}

The VIL was used as a benchmark for the achievement of the biopsy, the positive results were more straightforward and easier to read than those obtained by VIA. To date, 191 (68.21\%) biopsies have been completed, of which 102 (80.95\%) were completed in the 2017 and 89 (57.8\%) were completed in the 2018 crop year. To date, $136(71.20 \%)$ results have been achieved. The distribution of all lesions was by age (Table III). For example, several types of lesions were found for all of the tests. There were as many IELG $(4.77 \%)$ as there were IELHG $(4.48 \%)$. GBIPs were most often found in age groups 15-24 (8.47\%) and tended to disappear among those over 50 (1.27\%). For IELHGs, the age group most affected was $40-50$ years $(11.84 \%)$ and under 50 years (1.91\%). Eight cases of cervical cancer were found, with an incidence of $0.58 \%$ and $5.89 \%$ of all lesions. This lesion was found in all age groups and significantly higher in $15-24$ years (2.54\% versus $0.96 \%$ ).

\section{Support}

We took care of 136 lesions. These are 66 IELG (48.53\%), 62 IELHG (45.59\%) and 8 invasive cancers (5.89\%). Monitoring was reported for the IELG and under age 50. The survey was carried out 59 times (43.39\%). It was done in women under the age of 40 with IELHG or invasive cancer. Hysterectomy was performed 11 times (8.08\%). It was reported for women over 40 years of age with IELHG or invasive cancer (Tables 3\&4).

Table 3: Distribution of histological lesions by age.

\begin{tabular}{|c|c|c|c|c|c|}
\hline \multirow{3}{*}{$\begin{array}{l}\text { Age range } \\
\text { (an) }\end{array}$} & \multicolumn{4}{|c|}{ Type of lesions } & \multirow{3}{*}{$\begin{array}{c}\text { Total } \\
\text { lesions } \\
\text { (HG et } \\
\text { cancer) }\end{array}$} \\
\hline & \multirow{2}{*}{$\begin{array}{l}\text { Total } \\
\text { age }\end{array}$} & \multicolumn{2}{|c|}{ IEL* } & \multirow[t]{2}{*}{ Cancer } & \\
\hline & & IELG & IELHG & & \\
\hline & $\mathrm{N}$ & $\mathrm{n} / \%$ & $\mathrm{n} / \%$ & $\mathrm{n} / \%$ & $\mathrm{n} / \%$ \\
\hline $15-24$ & 118 & $10 / 8,47$ & $4 / 3,39$ & $3 / 2,54$ & $7 / 5,93$ \\
\hline $25-39$ & 724 & $41 / 5,66$ & $25 / 3,45$ & $1 / 0,28$ & $26 / 3,59$ \\
\hline $40-50$ & 228 & $11 / 4,82$ & $27 / 11,84$ & $1 / 0,44$ & $28 / 12,28$ \\
\hline Plus de 50 & 314 & $4 / 1,27$ & $6 / 1,91$ & $3 / 0,96$ & $9 / 2,87$ \\
\hline Total & 1384 & $66 / 4,77$ & $62 / 4,48$ & $8 / 0,58$ & $70 / 5,06$ \\
\hline
\end{tabular}

${ }^{*}$ IEL: Intra-epithelial lesion, BG: low grade, HG: High grade

Table 4: Practical attitude according to observed injury.

\begin{tabular}{|c|c|c|c|c|}
\hline \multicolumn{5}{|c|}{ Type of lesion } \\
\hline Injury type & IELG & IELHG & Cancer & Total \\
\hline & $\mathrm{n} / \%$ & $\mathrm{n} / \%$ & $\mathrm{n} / \%$ & $\mathrm{n} / \%$ \\
\hline Monitoring & $66 / 48,53$ & 0 & 0 & $66 / 48,53$ \\
\hline Conization & 0 & $56 / 41,18$ & $3 / 2,21$ & $59 / 43,38$ \\
\hline Hysterectomy & 0 & $6 / 4,41$ & $5 / 3,68$ & $11 / 8,08$ \\
\hline
\end{tabular}

\section{Discussion}

Cervical cancer is the most common cancer and the leading cause of cancer deaths among women in developing countries. High 
incidence is observed in Africa with rates above 50 per 100,000 and age-standardized mortality rates sometimes exceeding 40 per 100,000 . The major risk factor is human papilloma virus (HPV) infection and its co-infection with human immunodeficiency virus (HIV) accelerates its evolution towards cancer $[3,4]$. In our context, primary prevention based on healthy lifestyles and immunization is difficult. In addition, the clinical tables found require heavy care and even palliative care [10]. Secondary prevention is an effective alternative in our low-resource regions. It is done through screening for pre-cancer lesions and early diagnosis of cancer and treatment. Visual screening of the cervix followed by cytological analysis showed its effectiveness and performance. In our environment, despite the information campaigns, screening remains low and demand is lower. Mass campaigns have the benefit of mobilizing women's populations and benefit the large number [8,9]. For the past two years, October has mobilized women from the city of Owendo and the surrounding area. In 2017, women numbered 629 and in 2018,755 , or a rise of $9.1 \%$. The results of a campaign in Conakry showed a similar rise [11]. It is a testimony to a strong demand and presents women for cervical cancer screening. For several years, the local media, NGOs, the Ministry of Public Health and WHO have been promoting awareness campaigns on the prevention of sexually transmitted diseases and female cancers. This may explain this excitement and mobilization. In 2001, a study carried out in Libreville at the medical school's anatomy pathology laboratory showed an average of 570 screenings per year [12]. All age groups were involved with strong mobilization for those aged 25-39 (52.3\%) and a downward trend at both ends of the age. This patient profile is identical to that found by Leno, et al in Conakry and Mpiga E, et al. in Libreville $[11,13]$. Young and educated populations are more sensitive and more accessible to information. They are suitable for prevention and readily accept screening and associated treatments. The level of education is an asset to the success of prevention campaigns [14]. That was the case in our series. The majority of the populations studied were single, most multigested women, $63.73 \%$ had a history of STI and $64.72 \%$ had more than 5 sexual partners. This sample reflects the population of our country. It is no longer necessary to demonstrate that sexual activity is the main risk factor for the development of cervical cancer $[15,16]$. This encourages the proliferation of such campaigns at the national level. There is a correlation between the importance of coverage and the decline in cervical cancer incidence and morbidity due to severe forms. Studies in several low-income countries have demonstrated the importance of mass screening, which is more beneficial than often costly individual screening $[14,17,18]$. The results after Lugol's application appeared easier to read. Iodo-negative areas were found in all age groups with no significant difference. However, it was further recovered as management; the number of partners and the status of single were high. We collected 191 (68.21\%) targeted samples and received $136(71.2 \%)$ histological results. These figures are insufficient, and our procedure is contrary to the spirit of a screening campaign. The lack of material (biopsy tongs, methanol and transport media) does not allow us to regularly screen until histological results are not free. All samples showed cellular anomalies to varying degrees. This is confirmation that visual inspection methods have good sensitivity and positive predictive value $[19,20,21]$. It is a good screening test adapted to our working conditions and resources, unlike cervico-uterine smears, which are more difficult to do in our context [22]. We found as many IELG as IELHG $(4.77 \%$ vs $4.48 \%$ ). This conforming classification has proved easier for us to support [23]. IELG were less recovered when age was advanced. The prevalence of these lesions in young populations proves that cervical cancer is a slow-growing cancer. It starts early in young women sexually active. He is thus found to varying degrees in all age groups. Our results are not far from those of Leno and coll in Conakry [11]. We have detected $8(0.58 \%)$ invasive cancers of the cervix. The incidence of the cancer found in our series appears low compared to those of other series [11,13]. This figure could be seen rising because we did not regularly review all suspicious lesions, and it was similarly carried out biopsies. The cancer is found at all ages. It is significantly present in the 15-24 age group. The incidence of precancerous lesions and that of cancer tend to decrease with the level of education up women, lifestyle, the multiplication of screening tests and the immediate management of lesions detected [20]. All lesions have been supported. The IELHG received a conization majority (41.18\%). It was often performed at the cold knife given partial unavailability of the Cove diadermic and we don't have destructive means, such as the coagulation gold or cryotherapy. In terms of literature, cryotherapy appears as a method of 1st line for the support of precancerous lesions, even if it often arises the problem of transition to the healthy zone [24]. Our institution should develop such means for the easy management of the entire lesion. For 8 cancers detected 3 conisations and 5 colpohysterectomy were conducted in accordance with the recommendations of the multidisciplinary consultation meetings (MCM). Support of precancerous lesions and cancer is fully supported by the health insurance fund at the Institute of Oncology of Libreville. All channels of the treatment are carried out and very few evacuations for breast and Gynecologic cancer are rare in our context.

\section{Conclusion}

Cervical cancer is a common cancer in our environment. Its current impact is underestimated. It is a cancer of young women. This cancer begins very early and is found in all age groups. Screening campaigns have a real benefit. They enable a large number of women and all sectors of society to be mobilized. It is essential to achieve this in other regions of Gabon. Visual inspection methods have proved their effectiveness by their simplicity and are compatible with our practices and our means. However, for its success, we have to make the whole chain of lesion management observed easy and possible.

\section{Acknowledgement}

Sima Olé B and Mounguengui CO designed the research protocol and wrote this manuscript Mba Edou SG, Madi TG, Assoume D and others. In Mewie Lendzinga collected the data Bang Ntamack JA, 
Mayi Tsonga S, Ngou Mve Ngou JP and Meye JF corrected and gave the form to this manuscript. All authors approved the final version of this manuscript.

\section{Conflict of Interest}

The authors declare no conflict of interest.

\section{References}

1. Ferlay J, Soerjomataram I, Dikshit R, Eser S, Mathers C, et al. (2015) Cancer incidence and mortality worldwide: sources, methods and major patterns in GLOBOCAN 2012. Int J Cancer 136(5): E359-E386.

2. GLOBOCAN 2012, Cancer Incidence and Mortality Worldwide: IARC Cancer Base No. 11 Lyon, France: International Agency for Research on Cancer; 2013.

3. Asiaf A, Ahmad ST, Mohammad So, Zargar MA (2014) Review of current knowledge on the epidemiology, pathogenesis end prevention of human papillomavirus infection. Eur J Cancer Prev 23(3): 206-224.

4. Cronjé HS (2005) Screening for cervical cancer in the developing world countries. Best Prat Res Clin Obstet Gynaecol 19(4): 517-529.

5. zur Hausen H (1996) Papillomavirus infection a major cause of human cancers. Biochim Biophy Acta 1288(2): F55-F78.

6. Monsonego J (2007) Prevention of cervical cancer: prophylactic HPV vaccination, current knowledge, practical modalities and new challenges. Press Med 36(4-Pt 2): 640-666.

7. Goldie SJ, Gaffikin L, Goldhaber-Fiebert JD, Gordillo-Tobar A, Levin C, et al. (2005) Cost effectiveness of cervical screening in five developing countries. N Engl J Med 353(20): 2158-2168.

8. Anorlu RI, Ola ER, Abudu 00 (2007) Low cost methods for secondary prevention of cervical cancer in developing countries. Niger Postgrad Med J 14(3): 242-246.

9. Lavoué V, Bergeron C, Riethmuller D, Daraï E, Mergui JL, et al. (2010) A new paradigm for cervical cancer screening. J Gynecol Obstet Biol Reprod (Paris) 39(2): 102-115.

10. Nze-Nguema F, Sankaranarayanan R, Barthelemy M, Nguizi-Ogoula S, Whelan S, et al. (1996) Cancer in Gabon, 1984-1993: a pathology registry based relative frequency study. Bull Cancer 83(9): 693-696.

11. Leno DWA, Diallo FD, Camara AY, Magassouba M, Komano FD, et al. (2017) Analysis of the results of cervical cancer screening campaigns in Conakry, Guinea. Bull Cancer 104(11): 104-120.
12. Meye JF, Mabika B, Belembaogo E, Engongah-Beka T, Minko-Mi Etoua D (2001) Place of cervical cancer screening in Gabon, 19-year study: 19771995. Annal Pathol 21(3): 233-236.

13. Mpiga E, Ivanga M, Koumakpayi IH, Ankély JC, et al. (2015) EngohanAloghe C, Interest in visual inspection with acetic acid and Lugol solute with colposcopy in cervical lesions in Gabon. Pan Af Med J Open Access 22: 165.

14. Gage JC, Ferreccio C, Gonzales M, Arroyo R, Huivín M, et al. (2003) Follow-up care women with an abnormal cytology in a low-resource setting. Cancer Detect Prev 27(6): 466-471.

15. Nwachokor FN, Forae GC (2013) Morphological spectrum of nonneoplasia lesion of the uterine cervix in Warri, South-South Nigeria. Niger J Clin Pract 16(4): 429-432.

16. Bentsi C, Klufio CA, Perine PL, Bell TA, Cles LD, et al. (1985) Genital infection with Chlamydia trachomatis and Neisseria gonorrhoeae in Ghanaian women. Genitourin Med 61(1): 48-50.

17. N'Golet A, Koutoupot BR, Lubuélé L, Moukassa D, Etoka SE (2004) Intraepithelial cervical neoplasia (CIN) in Brazzaville, Congo. Situation analysis. Ann Pathol 24(4): 324-328.

18. Mathers LJ, Wigton TR, Leonhardt JG (2005) Leonhardt and coll. Screening for cervical neoplasia in an unselected rural Guatemala population using direct visual inspection after acetic acid application a pilot study. J Lower Genit Tract Dis 9(4): 232-235.

19. Dumont A, Bessières N, Benbassa A, Razafindrafara G, Rabearison F (2017) Screening for cervical cancer in rural Madagascar; feasibility, coverage and impact. J Gynecol Obstet Hum Reprod 46(4): 327-332.

20. Sankaranarayanan R, Basu P, Wesley RS, Mahe C, Keita N, et al. (2004) Accuracy of visual screening for cervical neoplasia: results from an IARC multicenter study in India and Africa. Int J Cancer 110(6): 907-913.

21. (1999) Visual inspection with acetic acid for cervical-cancer screening: test qualities in a primary-care setting. University of Zimbabwe/ JHPIEGO Cervical Cancer Project. Lancet 353(9156): 869-873.

22. Doris B, Boyer L, Lavoué V, Riou F, Henno S, et al. (2014) Pap smears in an epidemiologically exposed population: received ideas, facts and arguments. J Gynecol Obstet Biol Reprod 43(1): 26-34.

23. Cochand-Priollet B, Ziol (2006) Update on the Bethesda 2001 system. Annal Pathol 26(5): 382-388.

24. Castro W, Gage J, Gaffikin L, Ferreccio C, Sellors J, et al. (2003) Efficiency, safety and acceptability of cryotherapy: a systematic literature review. Cervical Cancer Issues in Depth \#1. Seattle WA: Alliance for Cervical Cancer. Cancer Prevention. 